\title{
Electronification Design Of Bill Payment Transactions Using Service Oriented Architecture (SOA) At Bank ABC
}

\author{
Toni Darmawan ${ }^{1}$, Ahmad Nurul Fajar ${ }^{2}$ \\ ${ }^{1,2}$ Information Systems Management Departement, BINUS Graduate Program-Master of Information Systems \\ Management, Bina Nusantara University Jakarta, Indonesia 11480 \\ 'toni.darmawan@binus.ac.id, ${ }^{2}$ afajar@binus.edu
}

\begin{abstract}
Nowadays the growth of the digital economy is growing rapidly. Almost all payment transactions already use technology, especially in the banking industry. One of the activities of financial transactions in banks is electronification of bill payment transactions and this has become a matter of special concern such as school / university bill payment transactions, tax bill payment transactions, drinking water company bill payment transactions, etc. To accelerate the process of integrating bill payment transactions into all payment provider companies online, of course must use the right concept so that the system can be more effective and efficient, namely using the concept of service oriented architecture (SOA) by using the enterprise service bus (ESB). ESB is used in order to integrate the banking system with the bill payment transaction billing system. In this research the Service Oriented Modeling and Architecture (SOMA) methodology will be applied as a guide in implementing SOA-based solutions. SOA was chosen because it has the nature of interoperability so that it can be relied upon in developing online bill payment transaction systems between bank systems and other systems despite having different system platforms.
\end{abstract}

Key words : service oriented architecture (SOA), service oriented modeling and architecture (SOMA), enterprise service bus (ESB), elektronifikasi, interoperability

\section{INTRODUCTION}

Technology in the banking has long been done. Current advance in technology era gives opportunities for business to evolve their practices. Business can utilize technology to create innovation in form of new product or new service [1]. Nowadays technology in banking is not only a supporter of operations but has become a determinant of the direction of bank operations. Almost all transaction activities in banking have utilized information technology such as deposit and withdrawal of money, remittances and others through various media machines or applications such as automated teller machines (ATM), mobile banking, internet banking and others.
In 2014, Bank Indonesia officially launched a national non-cash society aimed at increasing public awareness of the use of non-cash instruments. As a form of participation in forming a less cash society, Bank $\mathrm{ABC}$ will electronize all non-cash payment transactions, such as paying taxes and levies in all districts / cities, paying schools or universities, paying regional water companies and etc through all channels that are owned by Bank $\mathrm{ABC}$ such as automatic teller machines (ATM), cash management systems (CMS), mobile banking, web teller applications.

The growth of electronification of bill payment transactions at this time is arguably growing very fast, causing all banks to compete with one another in order to meet customer needs. Almost all transactions in banking are based on technology so that each bank collaborates with one another and develops strategies to quickly meet the needs to serve the public in conducting banking transactions easily, quickly and safely. With the rapid development of electronification of bill payment transactions, this has become an issue of special concern.

The application of SOA in digital banking technology, especially in the eletronification of bill payment transactions at Bank $\mathrm{ABC}$, is very appropriate to overcome differences in system platforms. SOA is a software development architecture technology that enables companies to integrate data with one another. In other words, SOA is an architecture that supports business integration as a connected service and becomes a path to innovation. SOA is also a technology-based and evolutionary business strategy for integrating various sources of information from different sources of code or platforms. The use of the SOA concept will certainly have a very good impact on Bank $A B C$ in improving services both to customers or the public in the implementation of non-cash transactions.

\section{LITERATURE REVIEW}

\subsection{Electronification}

The definition of electronification is to change the mode of payment which was originally using cash to become non-cash [2]. Electronification of payment systems has developed in 
banks through several payment channels such as automatic teller machines (ATM), mobile banking, internet banking and so on with features such as balance information, transfer of funds both to fellow banks and between banks in real time, withdrawing money, payments taxes, telephone bills, electricity bills, school payments and others.

\subsection{Service Oriented Architecture}

SOA or service oriented architecture is becoming a trend in the latest technology in technology. The SOA divides function into different units (services), which can be distributed through a network and combined and reused to form business applications [3]. According to [4] SOA is an architecture that is service oriented, namely architecture that divides a problem into a variety of small services that work together. By using SOA an application is no longer seen in terms of technology, data, implementation environment but rather in terms of the services provided. In this way an application can communicate and cooperate with other applications regardless of technology, data, implementation environment of the application.

SOA is a framework for integrating business processes and supporting information technology infrastructure and standardizing service components that can be reused and combined according to business priorities. SOA is loosely coupled (low level of dependency between components), highly interoperable, reusable and interoperability (can communicate between platforms) [5].

According to [6] the SOA method has been adapted from the many experiences learned from the difficulties and challenges faced by the initial design of SOA project implementation. The main key to the purpose of using this experience is to make it a set of task roles that are used as a guide and best practice from the field concerned using service orientation.

SOA consists of a set of services, but a set of services is not enough to form an architecture. SOA consists of four components, that are [7] :

a. Message, is the data needed to complete a part or a work unit, which is exchanged between one service with another service.

b. Operation, the functions owned by a service to process messages to produce something. These functions will later interact with each other to complete a work unit

c. Service, presents a set of related operations to complete a set of related work units.

d. Process, a business rule that determines which operations are used to achieve certain objectives.

Illustration of these four components can be seen in Figure 1 [7] :

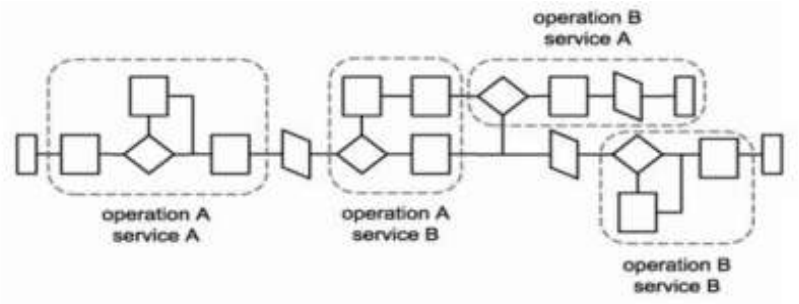

Figure 1: Illustration of Operations and Services [7] 2.3 Enterprise Service Bus

ESB is a joint infrastructure in the form of a large-scale computer network (enterprise) that can connect all system platforms in an organization. A service without ESB is certainly just an ordinary service. With the support of ESB, these services can be referred to as SOA. ESB can make services reused and simplify the composition of components on the server side.

Enterprise Service Bus or ESB is a flexible architecture that can be operated for integration between applications and services, this can reduce the number and complexity of interfaces in SOA architecture, improve business processes, integrating heterogeneous applications and can also increase the value of data assets. ESB is a combination of traditional middleware technology, including XML and web services, it provides a standard-based message exchange mechanism and other components through adapters and standard interfaces to meet application integration needs for large companies [8].

According to [9], [10] ESB is an infrastructure to integrate applications and services. ESB strengthens SOA through reducing the number, size, and interface complexity between applications and services. ESB is used to connect existing and new software components to build an SOA. ESB is required to connect to some information technology resources. ESB must be flexible to integrate and reinstall components according to the changes of business needs. ESB connects the components with loose bonds that it provide the ability to integrate systems into SOA and deploy gradually. The general architecture of ESB with connected components can be seen in Figure 2 :

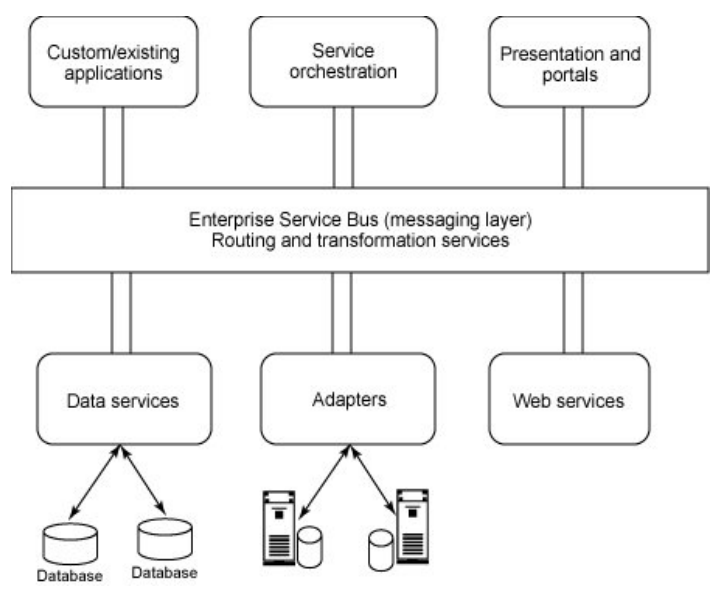

Figure 2: ESB Architecture [9], [10] 


\section{RESEARCH METHODOLOGY}

This study aims to integrate the Bank $\mathrm{ABC}$ system with other payment gateway systems that have different platforms with the service oriented modeling architecture (SOMA) development method. Following are the steps of the research method using SOMA:

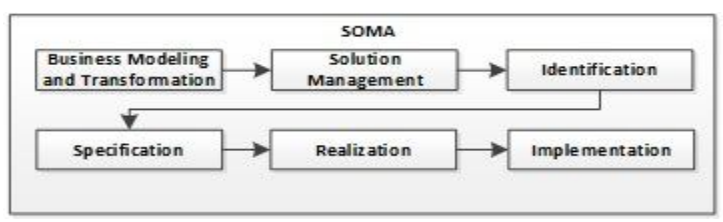

Figure 3: SOMA research Methodology

\section{RESULT AND DISCUSSION}

\subsection{Business Modeling and Transformation}

This stage is the first step in the SOMA method. This initial stage of the process is used to define business processes that are currently running at Bank $\mathrm{ABC}$ so that it will form a new business process that is reengineering business processes. Some of the approaches used that will describe business processes and value chain diagrams. An overview of the business processes currently running at Bank $A B C$ is as follows :

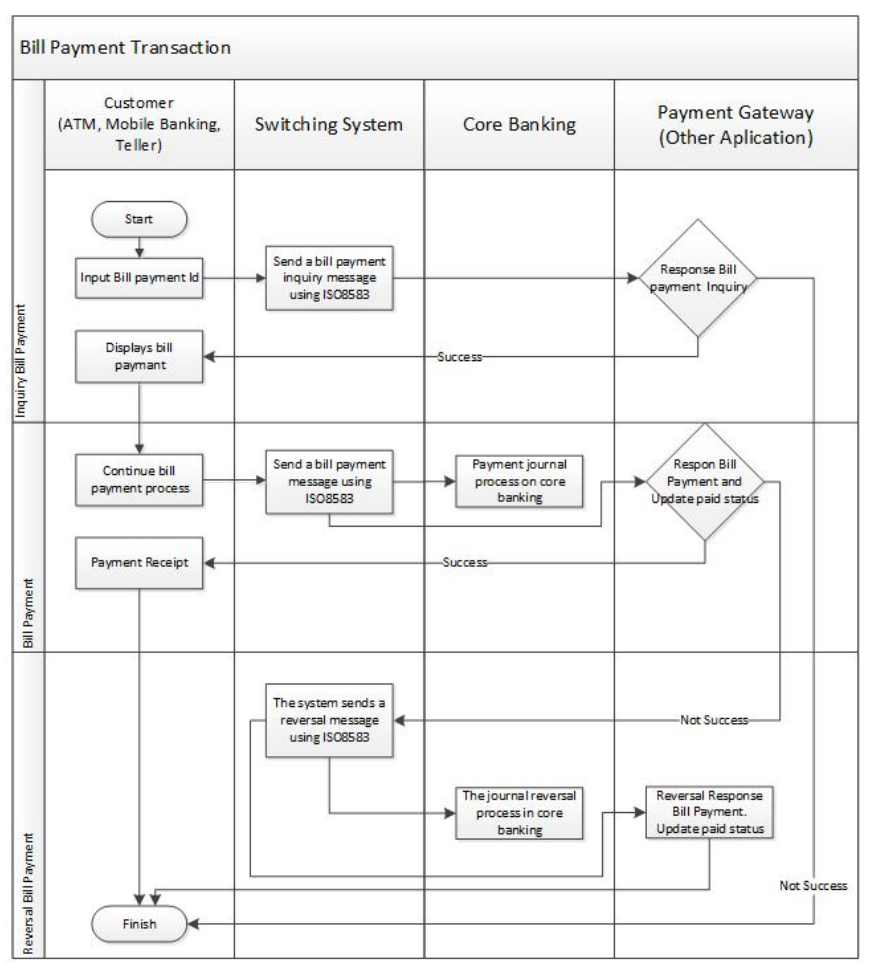

Figure 4: Business Proses currently (Source: Author)

\section{A. Use Case Diagram}

In the use case diagram illustrates the detailed stages of the business process associated with the actors in this system. The following use case bill payment system as illustrated below :

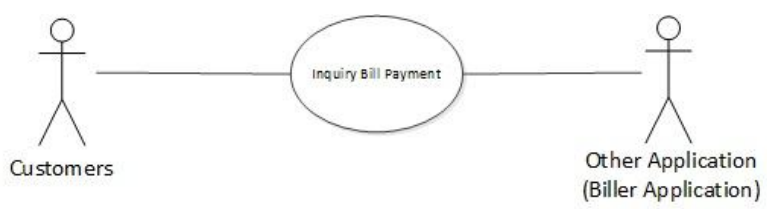

Figure 5: Use Case Diagram for inquiry payment (Source: Author)

In Figure 5 above illustrates that the customer of Bank ABC before making bill payment transactions, the customer can find out the amount of the bill first.

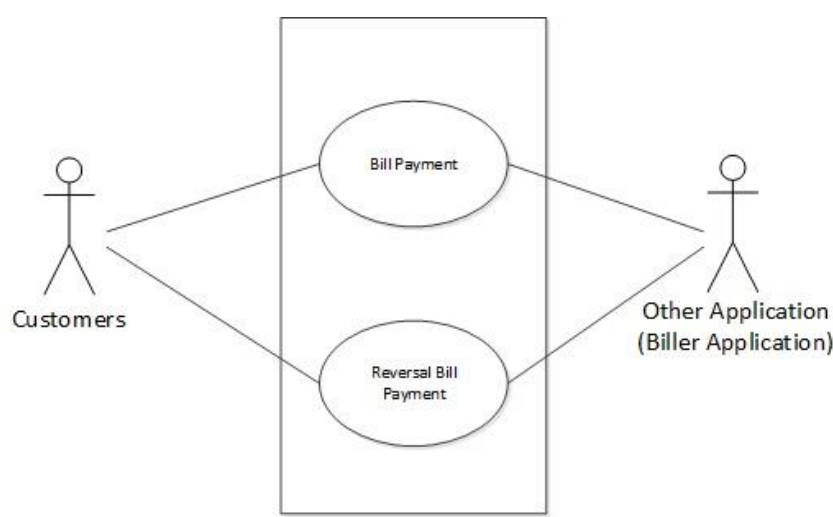

Figure 6: Use Case Diagram for Bill Payment and Reversal Bill Payment (Source: Author)

In Figure 6 above is the payment process carried out by Bank $\mathrm{ABC}$ customers in bill payment transactions and the reversal of bill payment transaction processes if abnormalities occur in the system that should occur.

\subsection{Solution Management}

In the second stage the SOMA method will be done to stabilize the solution, which is one of the processes that will be carried out is the selection of template solutions. This stage is used to solve problems encountered such as a space for service placement. The service to be developed will be placed in a service placement container using the enterprise service bus (ESB) as an integrator. The process of making containers for each service can be illustrated in the figure 8 : 


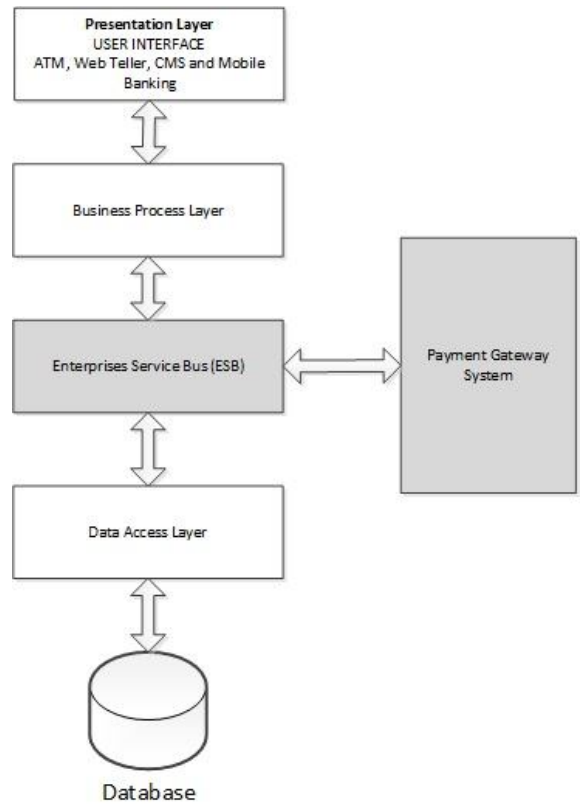

Figure 6: Solution Architecture (Source: Author)

\subsection{Identification}

Identification is the third step in the SOMA method. This stage starts from observing the bill payment transaction system using a web service. From these observations, a web service will be created which will be continued to the goal service modeling phase to sharpen the focus of service creation. After the solution has been obtained using the enterprise service bus, the decomposition process is then continued, which is used to identify the process in the system in the form of a candidate service that will be generated. Following the Decomposition Process as shown in the image below :

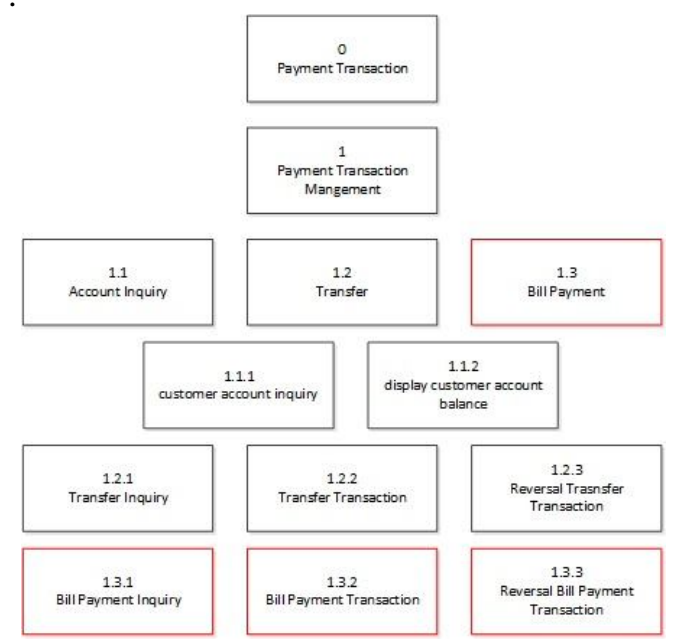

Figure 7: Process Decomposition (Source: Author)

\subsection{Specification}

This stage is a detailed specification of the service components to be used. In making the specifications of each service component to be used is divided into 2 main stages, namely the domain model to describe the relationship between entities in the system to be used and the component specifications to reflect the definition of service both in function and service quality. The following domain models are shown in the image below:

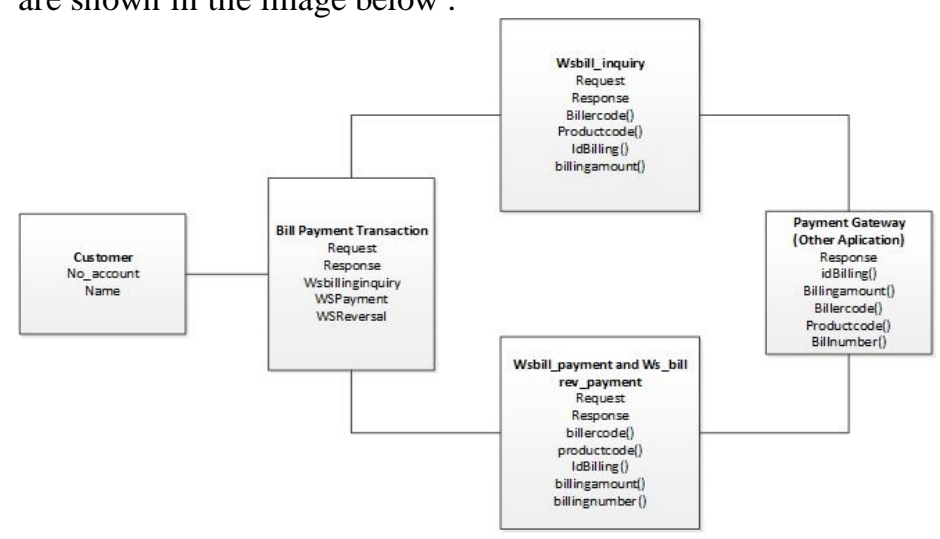

Figure 8:Domain Model (Source: Author)

\subsection{Realization}

Realization functions to connect various services that have been created previously and have been defined into components depicted in the SOA reference architecture. The proposed SOA Reference Architecture for bill payment transactions consists of bill payment inquiries, bill payment transactions and bill payment reversals by applying to the integration layer using the Enterprise Service Bus (ESB) which will be adjusted to business processes at Bank $A B C$.

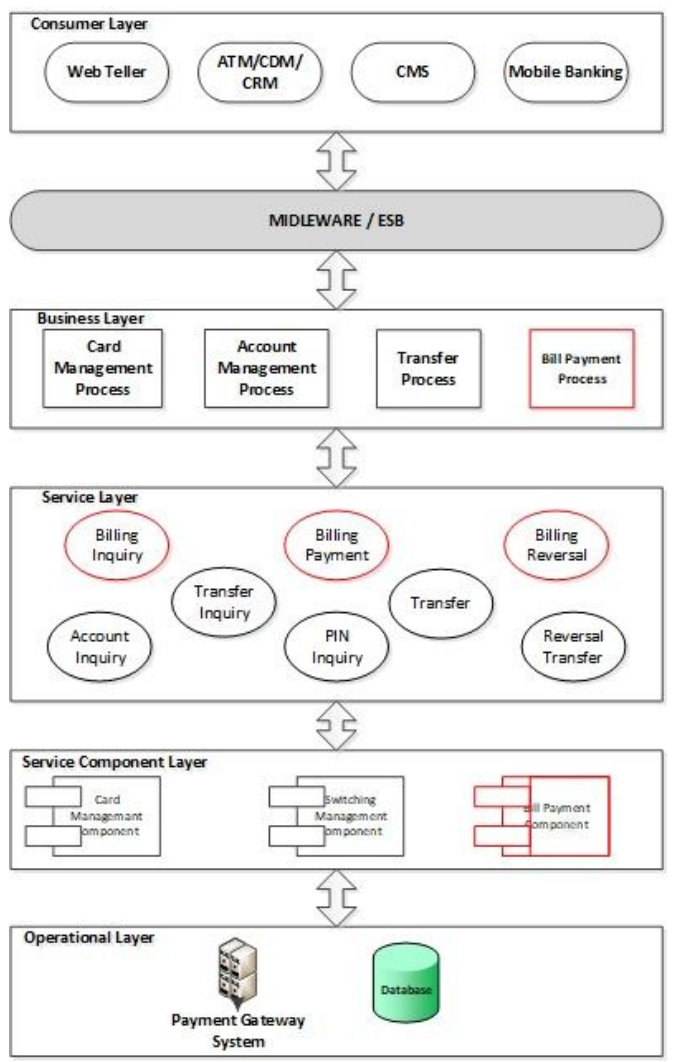

Figure 9: SOA Reference Architecture (Source: Author) 
Toni Darmawan et al., International Journal of Emerging Trends in Engineering Research, 8(4), April 2020, 1434 - 1438

\subsection{Implementation}

At this stage is how the system is implemented using the enterprise service bus which is then tested for each service to be implemented. In implementing the system, it must be followed by hardware and software will be planned that are used. List of software for building web services :

1. The operating system used uses Linux as an operating system.

2. Enterprise service bus using Apache ServiceMix with features in it consisting of Messaging using Apache ActiveMQ to provide remitting, clustering, reliability and distributed failover, Integration using Apache Camel for routing and mediation, RESTfull web services using Apache CFX.

List of hardware that will be used during implementation, that are :

1. Processor using Dual Quad Core 64bit

2. Ram using minimum $16 \mathrm{~GB}$

3. Hard disk using minimum 500 GB SCSI

4. Network using Gigabyte Ethernet

The next stage is to develop a web service in the context of electronification of bill payment transactions, that are : service inquiry bill payment, service bill payment and reversal bill payment service.

\section{CONCLUSION}

Based on the results of the study, several important things have been obtained which can be concluded from several descriptions electronification of the bill payment transaction that have been submitted that are :

1. The business process architecture design of bill payment transactions in an integrated Bank ABC uses the SOA approach by using ESB as integration middleware.

2. Service candidates have been produced that will be used as many as 3 (three) reusable services namely service bill payment inquiry, service bill payment and service bill reversal payment.

\section{REFERENCES}

[1] Wang, Gunawan, The Use of Internet of Things and Big Data to Improve Customer Data in Insurance Company. International Journal of Emerging Trends in Engineering Research. 7. 756-761. 10.30534/ijeter/2019/047122019, 2019

[2] Bank Indonesia, Edukasi, 2017, available at https://www.bi.go.id/id/edukasi-perlindungan-konsume n/edukasi/produk-dan-jasa-sp/elektronifikasi-dan-ki/Pa ges/default.aspx

[3] Ilham, Refito, The Design of SOA-based Applications for Electronic Medical Records in DKI Jakarta. International Journal of Emerging Trends in Engineering Research. 8. 606-510. 10.30534/ijeter/2020/53822020, 2020

[4] Erl, Thomas, Service Oriented Architecture:
Principles of Service Design, New Jersey, Pearson Education Inc, 2007

[5] Stenly R. Pungus, Penerapan Service Oriented Architecture Untuk Pengintegrasian Sistem Informasi Perguruan Tinggi Study Kasus di Klabat (UNKLAB) Manado, Tesis Program Master, Institut Teknologi Bandung, 2008

[6] Warkim, W. and Sensuse, D, Model Integrasi Sistem dengan Pendekatan Metode Service Oriented Architecture dan Model View Controller pada Pusat Penelitian Perkembangan Iptek Lembaga Ilmu Pengetahuan Indonesia. Jurnal Teknik Informatika dan Sistem Informasi. 3, 1 (Apr. 2017). DOI:https://doi.org/10.28932/jutisi.v3i1.656, 2017

[7] Erl, Thomas. Service-Oriented Architecture: Concepts, Technology, and Design, New Jersey: Prentice Hall, 2005

[8] Ma, X., Yao, Q.-b., \& Shan, S. The Study and Application of System Integration Based on ESB for Enterprise Group. International Conference on Wireless Communication and Network Engineering (WCNE 2017), Journal of DEStech Transactions on Computer Science and Engineering, Xiamen, China 2017

https://doi.org/10.12783/dtcse/wcne2017/19912

[9] Juric, M.B., Loganathan, R., Sarang, P., dan Jennings, F. SOA Approach to Integration, Packt Publishing, Birmingham, B27 6PA, UK, 2007

[10] Andary, J.F. and Sage, A.P. The role of service oriented architectures in systems engineering, Information Knowledge Systems Management 9 (2010), IOS Press, 2010

https://doi.org/10.3233/IKS-2010-0159 